\title{
Occupational Stress and Instigator Workplace Incivility as Moderated by Personality: A Test of an Occupational Stress and Workplace Incivility Model
}

\author{
Laura Batista \\ Florida International University \\ Thomas G. Reio, Jr. \\ Florida International University
}

\begin{abstract}
This research investigates the relationship between occupational stress and instigator workplace incivility, as moderated by personality, to select organizational outcomes (i.e., perceived physical health and intent to turnover). Data were collected from 206 fulltime working adults in the healthcare industry utilizing Amazon MTurk. Moderated hierarchical regressions were conducted to test the possible moderating role of personality on the stress-incivility relationship; the results demonstrated that conscientiousness and agreeableness dampened the stress-incivility relationship and neuroticism and extraversion strengthened the relationship. Hierarchical regression analyses were conducted also to explore the degree stress and incivility predicted the outcome variables of perceived physical health and intentions to turnover; the data indicated support for the notion that greater stress and incivility positively predicted turnover intent.
\end{abstract}

\section{INTRODUCTION}

In the face of competing demands, global market demands and competition among organizations, employees are taxed to exert more effort with fewer resources. This challenging work environment can create the recipe for increased levels of occupational stress and an environment of increased workplace incivility (Griffiths, 1998; Schabracq \& Cooper, 2000). The current work environment requires employees to exert more effort or face negative consequences from supervisors and peers. All too often, the salary increases, bonus structure, career progression, job security and mobility that might be reasonably expected from producing such extra effort do not align with organizational reality. This vexing situation creates workplace settings in which employees would be more likely to release their frustrations generated by unmet expectations through engaging in uncivil behaviors (Reio \& Ghosh, 2009). This situation can be exacerbated further by individual differences (e.g., personality traits) in one's ability in handling such stressors in that certain personality types (e.g., low emotional stability) may find it harder to deal effectively with these demands. Consequently, it is imperative for organizational researchers (e.g., human resource) and professionals (e.g., human resource practitioners, line managers) to understand the workplace dynamics that enhance employee well-being (e.g., reducing occupational stress) and become 
attuned to incidences of uncivil behaviors that can jeopardize functioning productively at work (Estes \& Wang, 2008; Ghosh, Jacobs \& Reio, 2011; Gilbreath \& Montesino, 2006).

The purpose of this study was to explore the relationship between occupational stress and workplace incivility (instigator) as moderated by personality with select organizational outcomes (i.e., perceived physical health and intent to turnover). Through this research and its findings, it will help enrich the research literature by further demonstrating a link between occupational stress and workplace incivility and how individual difference factors (i.e., personality traits) play a role in this relationship. Additionally, the findings of this study will help to guide practice, by using the further understanding gained from this study to implement programs in the workplace which will lead to decrease intention to turnover and increase physical health.

Stress is not a new concept, as it was first described and operationalized well over 50 years ago. Selye (1936) defined stress as a non-specific response to stimuli. As the world of work has become more technologically sophisticated, and the line between work and home has been blurred, so has the definition of stress expanded beyond a response to a stimulus and it has now been presented in three categories or approaches: (a) engineering approach, in which stress is described as a level of demand; (b) physiological approach, stress is defined by the physiological changes undergone by the person while they are in a state of stress; and (c) psychological approach, this approach defines stress as an interaction between individuals and their environment (Cox \& Griffiths, 1995). There are several models of occupational stress that align with one of the approaches mentioned above to define stress. A strong body of evidence indicates that exposure to adverse psychosocial work conditions is a major hazard for the health of workers in modern economies (Hodgson, Jones, Elliot, \& Osman, 1993; Karasek, 1979). Physical conditions of stress are: hypertension, heart disease, strokes, diabetes, and ulcers, to name a few (Karasek, 1979). The psychological conditions that result from stress are: depression, accidents, suicidal behavior, alcoholism, substance abuse (Gabriel, 2000; Wang \& Pattern, 2001).

Workplace incivility is another factor affecting the workplace today. As with occupational stress, workplace incivility has also been associated negatively with employee perceptions of physical health, organizational commitment, and job satisfaction (Reio \& Ghosh, 2009), as well as health-related issues that decrease productivity and ultimately the organizations bottom line (Porath \& Pearson, 2013).

Occupational stress also impacts employee behavior. Workplace incivility has been found to occur in chronic stressful work environments, like healthcare settings (Johnson \& Indvik, 2001). Andersson and Pearson (1999) define workplace incivility as a "low-intensity deviant behavior with ambiguous intent to harm the target, in violation of workplace norms for mutual respect" (p. 457). Specifically, "uncivil behaviors are characteristically rude and discourteous, displaying a lack of regard for others" (p. 457). Similar to occupational stress, scholars have found negative health-related outcomes in work environments which are characterized by uncivil behavior (Lim, Cortina \& Magley, 2008). Consequently, occupational stress and workplace incivility lead to loss of work days due to health-related issues, as well as having a negative impact on individuals' mental health.

Indeed, the world of work continues to change. The continued advances in technology have created blurred lines between work and home life (Schabracq \& Cooper, 2000). It is less clear to employees when work ends and home life begins, making it all-too-easy for work to spill over into one's home life. Thus, it is important to understand how we can mitigate the negative impact of stress on employees in workplace settings. There is a gap in the current literature which fails to address the possible link between workplace incivility and occupational stress and its concomitant organizational outcomes, such as declined perceived physical health and turnover intent (a strong predictor of actual voluntary turnover). Workplace incivility tends to be examined from either the target, onlooker or instigator perspective (Reio \& Ghosh, 2009). We need more research about how incivility affects organizational outcomes, especially from an instigator perspective because so little research has examined this type of incivility. Having a clear understanding of a link between stress and workplace incivility from an instigator perspective will inform organizational researchers and professionals of possible organizational programs to put in place to lessen the negative organizational outcomes (e.g., decreased productivity, absences, greater turnover intent, decreased job performance and satisfaction). 
Additionally, while it is important to understand how occupational stress may be linked to the incidence of workplace incivility, promising moderator variables that might strengthen or weaken the relationship between the two variables must be investigated as well because so little research exists currently. Individual difference variables, such as personality traits, may be critical moderators of the stress-incivility relationship. Emotional stability, for example, has been shown to be linked to both stress and incivility (Reio, 2011), but not tested as a moderator between the two variables. Additionally, both conscientiousness and agreeableness have been found to have a negative relationship to stress and counterproductive work behaviors (Bowling \& Eschleman, 2010). However, negative affectivity has been found to have a positive relationship with stress and a closely related construct, counterproductive workplace behavior (Bowling \& Eschleman, 2010). The new insights gained from testing personality trait moderators of the relationship between stress and incivility might be useful for guiding future theory building, empirical research and practice-related efforts.

The current study will be guided by Lazarus and Folkman's (1984) transactional approach of occupational stress, specifically using the social environmental and the person-environment-fit models (i.e., role ambiguity, role conflict, and organizational constraint). The researchers used the Social Environment model, which is also referred to as the Institute of Social Research (ISR), to explore the relationship between occupational stress and both health- and organizational-related outcomes (Choi, Kawakami, Chang, Koh, Bjorner, Punnett \& Karasek, 2008; Probst, 2010), as well as a component of the Person-Environment-Fit model, specifically understanding the experienced mismatch between the individual's goals and the supplies/equipment made available by the work environment. Additionally, Robinson and Bennett's (1995) typology of workplace incivility to understand the relationship between occupational stress and workplace incivility was employed. Further, the Big Five Factor model will be used to understand the role of personality in the relationship between occupational stress and workplace incivility. The Lexical Big Five Factor model is based on the research which cataloged trait words from the lexicon (from the English language dictionary). Researchers then identified the recurrent traits which derived from the lexical research (Topolewska, Skimina, Strus, Cieciuch \& Rowinski, 2014). The Lexical Big Five Factor model includes the following dimensions of personality: imagination/intellect (closely akin to openness to experience), conscientiousness, extraversion, agreeableness, and neuroticism (Goldberg, 1990, 1992; McCrae \& Costa, 1987). French, Caplan and Harrison's (1982) PersonEnvironment-Fit model explains the relationship between the experience of a mismatch between the individual's needs/goals and the resources, materials/equipment and organizational policies which make up the environmental characteristics. Employees experiencing this type of work environment report experiencing a high level of strain. Finally, French and Kahn's (1962) Social Environment model focuses on the impact of the environmental stressors (i.e., role ambiguity, role conflict, workload and work expectations) on the level of stress experienced by the individual.

The integration of the occupational stress models will help capture a more comprehensive view and study of occupational stress through exploring the dimensions of the environmental factors and incivility. Ostry, Kelly, Demers, Mustard and Hertzman (2003) found the combined models explained 11.7\% and $41.1 \%$ more variance respectively when combining the models, as opposed to using the models separately. Using the models together can increase our understanding of the nature of occupational stress and how it is associated with negative organizational outcomes like workplace incivility. For instance, Roberts, Scherer, and Bowyer (2011) found that occupational stress is an antecedent of workplace incivility. The authors found occupational stress increases employees' tendencies to engage in uncivil behaviors. Employees experiencing occupational stress had less emotional bandwidth to be able to cope with the stressors. Therefore, there was a tendency in these employees to express a higher amount of uncivil workplace behaviors. Dai, Collins, Yu, \& Fu (2008) conducted a study combining job stress models (job demand control and effort reward imbalance) to predict burnout. The authors found the effort-reward imbalance model explained emotional exhaustion and depersonalization, while social support was a predictor of personal accomplishment; both models demonstrated significant power in predicting the three dimensions of burnout. Adding the effort-reward imbalance to the study provided additional information about how to interpret the coping mechanisms of participants. Additional studies 
have also demonstrated increased predictive power by combining the job demand-control and the effortreward imbalance models (Dai et al., 2008).

As noted in the section above, employees' perceptions of control influence the relationship between occupational stress and strain. A greater sense of control reduces the sense of stress and strain. Social support also played a role in this relationship; supervisors trained on how to support esteem-building and provide meaningful recognition had employees with reduced levels of cortisol secretion (Theorell, Endad, Arnetz, \& Weingarten, 2001); that is, less cortisol secretion is linked with reduced stress levels. Mark and Smith (2008) proposed a combined and comprehensive model of occupational stress. The authors' initial findings support the important role of the relationship between demands, control and social support, especially from supervisors. Similarly, Spector $(1998,2002)$ proposed an occupational stress model highlighting again the pivotal role of control and support. The author also stressed understanding the coping mechanisms of individuals, so that the organization can better help them alleviate occupational stress.

Personality traits also fit into this study's conceptual model in that they have been linked to occupational stress and incivility. Working from Goldberg's $(1990,1992)$ Lexical Big Five Personality Model, the imagination/intellect, conscientiousness, extraversion, agreeableness, and neuroticism personality traits should each moderate the relationship between stress and incivility. For example, neuroticism has been linked to increased stress and uncivil behavior (Reio \& Sanders-Reio, 2011) because individuals high in this trait tend to react to more situations as being threatening and lack the coping skills required to manage stressful situations, which, in turn, can increase the likelihood of behaving rudely. Alternatively, imagination/intellect should moderate the stress-incivility link because a high level of this trait is associated with the willingness to try new things and being tolerant of uncertainty and rapid change. Being able to skillfully handle uncertainty leaves the individual less likely to feel increased level of stress and therefore behave uncivilly when pressed with the impulses of a rapidly changing workplace. Similar to imagination/intellect, conscientiousness and agreeableness should also moderate the stress-incivility linkage in that each should dampen the association between the variables. Thus, those who are high in any of these three traits would be better able to handle stress (McCrae \& Costa, 1987) and less likely to aggress in the form of uncivil behavior (Reio \& Sanders-Reio, 2011).

Robinson and Bennett's (1995) incivility typology includes two categories (organizational and individual) and four dimensions (property, production, political, and personal aggression). The two categories are critical to understanding the antecedents or drivers to the behavior and the dimensions aid in understanding the target of the behavior. The workplace incivility typology supports the notion that incivility is linked to negative organizational outcomes. For example, Reio and Ghosh (2009), using Bennett and Robinson's (2000) interpersonal incivility scale, found that perpetrator interpersonal incivility negatively predicted perceived physical health and job satisfaction. In a study of teacher incivility, Reio and Sanders-Reio (2011) discovered that $85 \%$ of the participants experienced incivility over the past year. Further, they reported that being the target of uncivil behavior from one's supervisor was associated with less organizational commitment and greater turnover intent, while coworker incivility did not explain additional variance in the regression equations. Pearson, Andersson and Wegner (2001) demonstrated that incivility matters to not only instigators and targets, but also witnesses or even those hearing about an incident because they too either withdraw more from the organization or join in the spiral of increasingly uncivil behavior. In summary, incivility has been shown to have pronounced linkages to negative organizational outcomes.

Based on the aforementioned literature, we propose the following hypotheses. When incivility is mentioned, the researchers are referring to instigator incivility, and not onlooker or target incivility, which is beyond the scope of this research. Further, for the purposes of this research, the imagination/intellect type of personality will be considered synonymous with McCrae and Costa's (1987) more commonly known openness to experience variable (Goldberg, 1992).

$\boldsymbol{H}_{1}: \quad$ Extraversion moderates the relationship between occupational stress and incivility, such that the stress-incivility relationship will be strengthened. 
$\boldsymbol{H}_{2}$ : Neuroticism moderates the relationship between occupational stress and incivility, such that the stress-incivility relationship will be strengthened.

$\boldsymbol{H}_{3}$ : $\quad$ Conscientiousness moderates the relationship between occupational stress and incivility, such that the stress-incivility relationship will be dampened.

$\boldsymbol{H}_{4}: \quad$ Agreeableness moderates the relationship between occupational stress and incivility, such that the stress-incivility relationship will be dampened.

$\boldsymbol{H}_{5}: \quad$ Imagination/intellect moderates the relationship between occupational stress and incivility, such that the stress-incivility relationship will be dampened.

H. $_{6} \quad$ After controlling for occupational stress, workplace incivility will be negatively related to perceived physical health.

H: $_{7}$ After controlling for occupational stress, workplace incivility will be positively related to turnover intention.

\section{METHOD}

\section{Participants}

The participants in this study were comprised of 206 working adults in the healthcare industry. Approximately $55 \%(n=114)$ of the sample was female and $45 \%(n=92) ; 7.8 \%(n=16)$ of the sample was Asian, 10.2\% $(n=21)$ was Black, $8.3 \%(n=17)$ was Hispanic, $70.9 \%(n=146)$ were White, and finally $2.9 \%(n=6)$ selected "other." Further, $34.0 \%(n=70)$ of the respondents indicated that their job function was direct patient care, $17.5 \%(n=36)$ of the respondents indicated that their job function was indirect patient care, and 48.5\% $(n=100)$ indicated that their job function was administrative. Last, $24.8 \%$ $(n=51)$ of the sample was in the 21-19 group, $50.0 \%(n=103)$ of the sample was in the 30-39 group, $17.0 \%(n=35)$ of the sample was in the $40-49$ group, $4.9 \%(n=10)$ of the sample was in the $50-59$ group, and finally $3.4 \%(n=7)$ of the sample was in the 60 and over age group.

The healthcare industry was selected because of the demonstrated link between the stressful nature of being healthcare professionals and their propensity to engage in uncivil behaviors, which have resulted in lost productivity, escalations to physical violence, and physical health detriments (Felblinger, 2008).

\section{Measures}

The survey battery consisted of seven scales. Role stressors were assessed using Abdel-Halim (1978) 10 -item scale. The scale includes five items from each of the role stressors; that is, role conflict and role ambiguity. The items are on a 5-point Likert scale ranging from very false (1) to very true (5). The sample items include "I feel certain about how much authority I have" (role conflict), "I receive incompatible requests from two or more people," and "It seems like I have too much work for one person to do" (role ambiguity). The authors reported reliability coefficients for role conflict was .76 and role ambiguity was .69. For this study, the scales were not combined. For this study, the Cronbach's alpha for role conflict was .78 and .80 for role ambiguity.

Spector and Jex's (1998) 11-item organizational constraint (OCS) scale was used to measure the control latitude of each participant. Each item was on a 5-point Likert scale ranging from less than once per month or never (1) to several times per day (5). A sample item is "Conflicting job demands." The authors reported the coefficient alpha as .85. The Cronbach's alpha for this study was .89. In addition, Bennett and Robinson's (2000) 7-item Likert scale for interpersonal deviance was used to measure workplace incivility instigation. Each item is on a 7-point scale from never (1) to daily (7). A sample of an interpersonal deviance item is "Made fun of someone at work," and a sample of an organizational deviance item is "Put little effort into your work." The authors reported Cronbach's alphas for the 
interpersonal incivility as .81 . The Cronbach's alpha found in this study for interpersonal deviance was .85 .

Imagination/intellect, conscientiousness, extraversion, agreeableness, and neuroticism were assessed using the 20-item Mini Big Five Factor Markers of the International Personality Item Pool Assessment (Donnellan, Oswald, Baird, \& Lucas, 2006; McCrae \& Costa, 1987). Each item was on a 7-point Likert scale from strongly disagree (1) to strongly agree (7). Each subscale consisted of 4 items. A sample imagination/intellect item is "Have a vivid imagination." A sample conscientiousness item is "Make plans and stick to them." A sample extraversion item is "Make friends easily." A sample agreeableness item is "Believe others have good intentions." A sample neuroticism item is "Feel comfortable with myself." The authors reported Cronbach's alpha for each scale as the following: Imagination/intellect .85, Conscientiousness .92, Extraversion .95, Agreeableness .88, and Neuroticism .93. The Cronbach's alphas found in this study are the following: Imagination/intellect (Openness to Experience) .72, Conscientiousness .72, Extraversion .82, Agreeableness .74, and Neuroticism .78.

Cassidy's (2000) 6-item Perceived Physical Health Scale was used to measure participants' perceived physical health. Each item was on a 5-point scale ranging from never (1) to always (5). The Cronbach's alpha found in this study was .85. Intention to turnover was measured using Camman, Fichman, Jenkins, and Klesh's (1979) 3-item scale. The items included: (a) "I often think of leaving the organization," (b) "It is very possible that I will look for a new job in the next year," and (c) "If I could choose again, I would choose to work for the current organization" (reverse scored). The Cronbach's alpha reported for this scale was .77. The Cronbach's alpha found for this study was .72.

Strahan and Gerbasi's (1972) 10-item social desirability scale was used to measure participant's degree of concern to respond in a manner which demonstrates social desirability. A sample item includes "I would never think of letting someone else be punished for my wrong doing." The reliability coefficient reported in previous research for this scale has ranged from .55-.67 (Reio, 2010). The Cronbach's alpha for this study was .75 .

Participants' background (i.e., gender, age, race, level of education, current job function (e.g., direct patient care), and years of experience) were also collected using a 6-item demographic questionnaire. Each of the demographic variables has been shown to have significant relationships with both role stressors and incivility, except level of education (see Reio \& Ghosh, 2009; Reio \& Sanders-Reio, 2011). Level of education, on the other hand, has been linked to social desirability in that it decreases as years of education increases (Heerwig \& McCabe, 2009); consequently, it was included also in this research as a control variable.

\section{Procedure}

Amazon's Mechanical Turk (MTurk) electronic (Internet-based) survey tool was used to collect data for this study. To determine the completion time for the administration of the survey battery, as well as the clarity of the instructions and items, a pilot test was conducted with five individuals (Dillman \& Bowker, 2000). Guided by Dillman, Smyth, and Christian's (2009) protocol for conducting internet-based research, the researcher conducted a pilot study with five individuals similar to the population of this study to provide information in terms of the length of time needed to complete the survey, ease of answering questions, and to set the procedures for the survey research. The participants received a link to complete the electronic survey. The participants in the pilot study completed the instrument in about 1215 minutes. The participants indicated that the instructions to complete the instrument were clear, as well that the questions and answer options were also clear and easy to understand. There were no problems reported through the pilot study, except that two demographic questions were deemed confusing and therefore superfluous (employee status and job title) and the questions were deleted from the final study.

\section{RESULTS}

Moderated regression analyses were run for hypotheses 1-5, two sets of moderated hierarchical regressions were conducted to account for each workplace incivility (interpersonal deviance and 
organizational deviance) variable. In the first step of all the moderated regressions for the workplace incivility variables of interpersonal and organizational deviance, one variable was included: social desirability to control for the possibility of impression management as the respondents completed the selfassessment. PROCESS for SPSS (Hayes, 2012) was used and separate regression lines were plotted to interpret the interaction effects.

H1 stated that extraversion moderates the relationship between occupational stress and incivility, such that the stress-incivility relationship will be strengthened. For step one to predict interpersonal deviance with role ambiguity and the personality interactions, social desirability was added, $R 2=.015, F(1,204)=$ $3.147, p>.05$. The second step added the occupational stress variable of role ambiguity, $\Delta R 2=.012, F(1$, $203)=2.500, p<.05$. The third and last step added the interaction variables of the five personality traits, which accounted for a significant proportion of the variance in workplace incivility, $\Delta R 2=.187, F(5$, $198)=9.441, p<.001$. The results indicated that there was a positive main effect for participants' role ambiguity $(\beta=.15, p<.05)$ on interpersonal deviance in the third model. This suggests that role ambiguity has a unique positive effect on interpersonal deviance in that greater role ambiguity was associated with more interpersonal deviance. The interaction between role ambiguity and extraversion was significant $(B=.040, S E=.01, \beta=.28, p<.001)$. In the first step to predict interpersonal deviance with role conflict and the personality trait interactions, social desirability was entered, $R 2=.015, F(1$, $204)=3.147, p>.05$. The second step added the occupational stress variable of role conflict, $\Delta R 2=.038$, $F(1,203)=8.129, p<.01$. The third and last step added the interaction variables of the five personality traits, which accounted for a significant proportion of the variance in workplace incivility, $\Delta R 2=.156$, $F(5,198)=7.78, p<.001$. The findings indicated that there was a positive main effect for participants' role conflict $(\beta=.20, p<.01)$ on interpersonal deviance in the third model. This suggests that role conflict has a unique positive effect on interpersonal deviance in that greater role conflict was associated with more interpersonal deviance. The interaction between role conflict and extraversion was also significant $(B=.022, S E=.01, \beta=.21, p<.01)$. In step one to predict interpersonal deviance with organizational constraint and the personality trait interactions, social desirability was entered, $R 2=.015$, $F(1,204)=3.147, p>.05$. The second step added the occupational stress variable of organizational constraint, $\Delta R 2=.10, F(1,203)=22.940, p<.001$. The third and last step added the interaction variables of the five personality traits, which accounted for a significant proportion of the variance in workplace incivility, $\Delta R 2=.187, \Delta F(5,198)=10.59, p<.001$. The findings indicated that there was a positive main effect for participants' organizational constraint $(\beta=.28, p<.001)$ on interpersonal deviance in the third model. This suggests that organizational constraint has a unique positive effect on interpersonal deviance in that greater organizational constraint was associated with more interpersonal deviance. The interaction between organizational constraint and extraversion was also significant $(B=.017, S E=.00, \beta=.25, p<$ .001). Thus, there was partial support for hypothesis one.

$\mathrm{H} 2$ stated that neuroticism moderates the relationship between occupational stress and incivility, such that the stress-incivility relationship will be strengthened. In step one to predict individual deviance with role ambiguity and the personality trait interactions, social desirability was entered, $R 2=.015, F(1,204)$ $=3.147, p>.05$. The second step added the occupational stress variable of role ambiguity, $\Delta R 2=$ $.012, F(1,203)=2.500, p>.05$. The third and last step added the interaction variables of the five personality traits, which accounted for a significant proportion of the variance in workplace incivility, $\Delta R 2=.187, F(5,198)=9.441, p<.001$. The findings indicated that there was a positive main effect for participants' role ambiguity $(\beta=.15, p<.05)$ on interpersonal deviance in the third model. This suggests that role ambiguity has a unique positive effect on interpersonal deviance in that greater role ambiguity was associated with more interpersonal deviance. The interaction between role ambiguity and neuroticism was also significant $(B=.05, S E=.01, \beta=.29, p<.001)$. In step one to predict interpersonal deviance with role conflict and the personality trait interactions, social desirability was entered, $R 2=.015, F(1$, $204)=3.147, p>.05$. The second step added the occupational stress variable of role conflict, $\Delta R 2=.038$, $F(1,203)=8.129, p<.05$. The third and last step added the interaction variables of the five personality traits, which accounted for a significant proportion of the variance in workplace incivility, $\Delta R 2=.156$, $F(5,198)=7.782, p<.001$. The findings indicated that there was a positive main effect for participants' 
role conflict $(\beta=.20, p<.01)$ on interpersonal deviance in the third model. This suggests that role conflict has a unique positive effect on interpersonal deviance in that greater role conflict was associated with more interpersonal deviance. The interaction between role conflict and neuroticism was significant $(B=.03, S E=.01, \beta=.25, p<.001)$. In step one to predict interpersonal deviance with organizational constraint and the personality trait interactions, social desirability was entered, $R 2=.015, F(1,204)$ $=3.147, p>.05$. The second step added the occupational stress variable of organizational constraint, $\Delta R 2$ $=.10, F(1,203)=22.94, p<.001$. The third and last step added the interaction variables of the five personality traits, which accounted for a significant proportion of the variance in workplace incivility, $\Delta R 2=.187, F(5,198)=10.59, p<.001$. The findings indicated that there was a positive main effect for participants' organizational constraint $(\beta=.28, p<.001)$ on interpersonal deviance in the third model. This suggests that organizational constraint has a unique positive effect on interpersonal deviance in that greater organizational constraint was associated with more interpersonal deviance. The interaction between organizational constraint and neuroticism was also significant $(B=.02, S E=.00, \beta=.28, p<$ .001). Consequently, there was partial support for hypothesis two.

H3 stated that conscientiousness moderates the relationship between occupational stress and incivility, such that the stress-incivility relationship will be dampened. When predicting organizational deviance with role ambiguity and the personality trait interactions, social desirability in the first step explained $R 2=.009, F(1,204)=1.826, p>.05$. The second step added the occupational stress variable of role ambiguity, $\Delta R 2=.096, F(1,203)=19.447, p<.001$. The third and last step added the interaction variables of personality, which accounted for a significant proportion of the variance in workplace incivility, $\Delta R 2=.141, F(5,198)=7.307, p<.001$. The results indicated that there was a positive main effect for participants' role ambiguity $(\beta=.30, p<.001)$ on organizational deviance in the third model. This suggests that role ambiguity has a unique positive effect on organizational deviance in that greater role ambiguity was associated with more organizational deviance. The interaction between role ambiguity and conscientiousness was significant $(B=-.09, S E=.02, \beta=-.32, p<.001)$. When predicting organizational deviance with role conflict and the personality trait interactions, social desirability in the first step explained $R 2=.009, F(1,204)=1.826, p>.05$. The second step added the occupational stress variable of role conflict, $\Delta R 2=.053, F(1,203)=11.44, p<.01$. The third and last step added the interaction variables of personality, which accounted for a significant proportion of the variance in workplace incivility, $\Delta R 2=.143, F(5,198)=7.098, p<.001$. The results indicated that there was a positive main effect for participants' role conflict $(\beta=.24, p<.001)$ on organizational deviance in the third model. This suggests that role conflict has a unique positive effect on organizational deviance in that greater role conflict was associated with more organizational deviance. The interaction between role conflict and conscientiousness was significant $(B=-.07, S E=.01, \beta=-.33, p<.001)$. There was partial support for hypothesis three.

H4 stated that agreeableness moderates the relationship between occupational stress and incivility, such that the stress-incivility relationship will be dampened. In step one to predict interpersonal deviance with organizational constraint and the personality trait interactions, social desirability was entered, $R 2=$ $.015, F(1,204)=3.147, p>.05$. The second step added the occupational stress variable of organizational constraint, $\Delta R 2=.10, F(1,203)=22.94, p<.001$. The third and last step added the interaction variables of the five personality traits, which accounted for a significant proportion of the variance in workplace incivility, $\Delta R 2=.187, F(5,198)=10.59, p<.001$. The findings indicated that there was a positive main effect for participants' organizational constraint $(\beta=.28, p<.001)$ on interpersonal deviance in the third model. This suggests that organizational constraint has a unique positive effect on interpersonal deviance in that greater organizational constraint was associated with more interpersonal deviance. The interaction between organizational constraint and agreeableness was significant $(B=-.01, S E=.01, \beta=-.14, p<$ $.05)$. There was partial support for hypothesis four.

H6 stated that after controlling for occupational stress, workplace incivility will predict perceived physical health. The hypothesis was not supported. The outcome variable which was examined is perceived physical health. In the first step social desirability was entered, $R 2=.001, F(1,204)=.298, p=$ .586. In the second step, the three occupational stress variables entered into the model were: 
organizational constraint, role ambiguity and role conflict, $\Delta R 2=.029, F(3,201)=1.992, p=.116$. In the third step, the interpersonal deviance variable was entered, $\Delta R 2=.027, F(3,200)=2.832, p<.061$. The data did not support hypothesis 6, meaning that after controlling for social desirability, neither the organizational stress nor the incivility variable predicted perceived physical health significantly.

H7 stated that after controlling for occupational stress, workplace incivility will predict intention to turnover. The hypothesis was partially supported. The outcome variable which was examined is intention to turnover. In the first step, social desirability was entered $R 2=.000, F(1,204)=.048, p=.826$. In the second step, the three occupational stress variables entered into the model were: organizational constraint, role ambiguity and role conflict, $\Delta R 2=.307, F(3,201)=29.698, p<.001$. In the third step, workplace incivility was entered, $\Delta R 2=.017, F(3,200)=2.507, p=.042$. The interpersonal deviance variable was a significant predictor in the regression equation. Therefore, the analyses demonstrated partial support for hypothesis 7.

\section{DISCUSSION}

The aim of the current study was to further explore the relationship between occupational stress and workplace incivility as moderated by personality, while understanding the outcomes of this relationship with perceived physical health and intention to turnover. The first five hypotheses indicated that there will be a relationship between occupational stress and instigator workplace incivility, which will be moderated by personality. Specifically, this study hypothesized that conscientiousness, agreeableness, and imagination/intellect will dampen the relationship. On the other hand, extraversion and neuroticism were hypothesized to strengthen the relationship between the two variables. The findings suggest that personality does play a role in the stress incivility relationship, whereas conscientiousness and agreeableness dampen the relationship and neuroticism and extraversion strengthened the relationship. Further, this study found that intention to turnover increases as workplace incivility also increases, and markedly so. The findings of this study are consistent with prior research on occupational stress, workplace incivility, and personality.

\section{IMPLICATIONS}

The finding of this study supports the proposed holistic model of occupational stress and workplace incivility, as moderated by personality. The literature has found clear relationships between occupational stress, workplace incivility and personality. Prior to this study, research exploring the stress-incivility relationship focused on only three personality variables: conscientiousness, agreeableness and neuroticism. The majority of prior research has also focused on utilizing a specific occupational stress model, as opposed to using an integrated occupational stress model.

This study also contributes to incivility theory by addressing the need to explore the precursors of workplace incivility through an instigator perspective (Reio \& Ghosh, 2009; Schilpzand, De Pater, \& Erez, 2016); based on the findings of this research, stress is one such precursor. This research also supports incivility theory (Andersson \& Pearson, 1999) in that the theory predicts that stress would elicit uncivil behaviors, which, in turn, would be linked to negative organizational outcomes. In this study, intention to turnover was that important negative outcome. In this study, individuals who experienced higher levels of role or environmental and instigated workplace incivility behaviors were more likely to have increased intention to turnover. This particular finding of this study can help organizational researchers look deeper at intention to turnover from a different perspective.

Practically speaking, the participants all worked in the healthcare industry and represented both direct and indirect patient care job functions. The literature has indicated that healthcare professionals work in a high stress environment, due to the nature of their profession, especially those that are direct patient care professionals (e.g., Felblinger, 2008). The job function for healthcare professionals, especially direct patient care staff is imperative in ensuring patient safety and quality care. Therefore, this study's finding has even more critical implications for managers to create and maintain a positive and reduced stress 
work environment for these professionals. Human resource professionals in conjunction with managers need to find ways of implementing proactive programs that might create positive environments focused on reducing uncivil behavior that would, in turn, increase employee well-being. Employee participation in such programs have been demonstrated to be effective in reducing the likelihood of the increased occupational stress manifesting in uncivil behaviors that are associated with increased turnover intentions and voluntary turnover (Reio \& Ghosh, 2009).

\section{LIMITATIONS AND RECOMMENDATIONS FOR FUTURE RESEARCH}

As with any research, there are limitations. The first limitation of this study is the use of a convenience sample of Amazon Mechanical Turk workers. Whereas the use of a heterogeneous convenience sample of such workers is common in organizational research, there should be caution in generalizing the results beyond this study.

The second limitation is the use of self-report measures for this study. The participants of this study completed self-report instruments. While there are many benefits of using self-reports; such as, being inexpensive, easy to use, and relatively easy to distribute, these type of measures may increase the possibility for introducing common source method variance producing inflated or deflated correlations among the variables of interest (Crampton \& Wagner, 1994). Common method variance is a potential problem whenever data are collected from a single source, which is the case for this study. There were several procedural and statistical steps taken to reduce the possibility of common method variance. First, procedurally, participants were assured of their anonymity (Reio, 2010). Second, Dillman et al.'s (2009) Tailored Design Method for internet surveying was followed to reduce the likelihood of coverage, sampling, measurement and nonresponse error. Moreover, in accordance with Dillman et al.'s (2009) direction, a pilot study was conducted which aided in creating clear instructions and procedures. As a statistical remedy, potential social desirability bias was statistically controlled to lessen the likelihood of introducing common method bias into the study. Future research could include other common method bias control remedies like using multiple sources of data or employing affect as a statistical control variable (see Reio, 2010)

Another potential limitation in this study involved asking participants to report their level of workplace incivility as the instigator. As such, social desirability bias can play a role in the participants' responses, because they have to indicate that they were the instigator of uncivil behavior. A social desirability scale was utilized to statistically control for this potential bias and the analyses demonstrated that this bias was not likely in this research study. The findings of this study are consistent with prior workplace incivility research (e.g., Reio \& Ghosh, 2009).

Researchers need to continue looking further into stress-incivility relationship to understand the interaction of the relationship with different personality variables. Researchers can continue to further test this model and include a physical symptom scale, as opposed to a perceived physical health scale to further understand the linkages between stress, incivility and health.

The previous literature on workplace incivility has focused primarily on the onlooker and target perspective of workplace incivility. This creates a reactive approach to deal with workplace incivility and leaves a gap in the literature in terms to understand why individuals engage in workplace incivility behaviors and which types of individuals would be predisposed to engage in these types of uncivil behaviors. As with this study, future research on workplace incivility should focus on the proactive approach to addressing workplace incivility by exploring further the instigator perspective and creating a deeper level of understanding in the engagement of workplace incivility behaviors.

\section{REFERENCES}

Abdel-Halim, A. A. (1978). Employee affective responses to organizational stress: moderating effects of job characteristics. Personnel Psychology, 31, 561-579. 
Andersson, L. M.., \& Pearson, C. M. (1999). Tit for tat? The spiraling effect of incivility in the workplace. Academy of Management Review, 24, 452-471.

Bennett, R. J., \& Robinson, S. L. (2000). Development of a measure of workplace deviance. Journal of Applied Psychology, 85, 349-360.

Bowling, N. A., \& Eschleman, K. J. (2010). Employee personality as a moderator of the relationship between work stressors and counterproductive work behavior. Journal of Occupational Health Psychology, 15, 91-103.

Camman, C., Fichman, M., Jenkins, D., \& Klesh, J. (1979). The Michigan organizational assessment scale. Unpublished manuscript. Ann Arbor, MI: University of Michigan.

Cassidy, T. (2000). Social background, achievement motivation, optimism and health: A longitudinal study. Counseling Psychology Quarterly, 13, 399-352.

Choi, B., Kawakami, N., Chang, S., Koh, S., Bjorner, J., Punnett, T., \& Karasek, R. (2008). A crossnationalstudy on the multidimensional characteristics of the five-item psychological demands scale of the job content questionnaire. International Journal of Behavioral Medicine, 15, 120 132.

Crampton, S. M., \& Wagner, J. A. (1994). Percept-percept inflation in micro organizational research: An investigation of prevalence and effect. Journal of Applied Psychology, 79, 67-76.

Cox, T., \& Griffiths, A. (1995). The nature and measurement of work stress: theory and practice. In J. R. Wilson \& E. N. Corlett (Eds.), Evaluation of human work: A practical ergonomics methodology. London: Taylor \& Francis.

Dai, J. M., Collins, S., Yu, H., \& Fu, H. (2008). Combining job stress models in predicting burnout by hierarchical multiple regressions: A cross-sectional investigation in Shanghai. Journal of Occupational and Environmental Medicine, 50, 785-790.

Dillman, D. A., \& Bowker, D. (2000, May). An experimental evaluation of left and right oriented screens for web questionnaires. Presentation to the annual meeting of the American Association for Public Opinion Research, Portland, Oregon. Retrieved from http://survey.sesrc.wsu.edu/dillman/papers.htm.

Dillman, D. A., Smyth, J. D., \& Christian, L. M. (2009). Internet, mail, and mixed-mode: The tailored design method ( $3^{\text {rd }}$ ed.). Hoboken, NJ: John Wiley \& Sons.

Donnellan, M. B., Oswald, F. L., Baird, B. M., \& Lucas, R. E. (2006). The mini-IPIP scales: Tiny-yet effective measures of the Big Five factors of personality. Psychological Assessment, 18, 192-203.

Estes, B., \& Wang, J. (2008). Workplace incivility: Impacts on individual and organizational performance. Human Resource Development Review, 7, 218-240.

Felblinger, D.M. (2008). Incivility and bullying in the workplace and nurses' shame responses. Journal of Obstetrics and Neonatal Nursing, 37, 234-241.

French, J. R. P., Jr., Caplan, R. D., \& Harrison, R. V. (1982). The mechanisms of job stress and strain. London: Wiley.

French, J. R. P., Jr., \& Kahn, R.L. (1962). A programmatic approach to studying the industrial environment and mental health. Journal of Social Issues, 18, 1-48.

Gabriel, P. (2000). Mental health in the workplace, International Labour Office, Geneva.

Ghosh, R., Jacobs, J. L., \& Reio, T. G., Jr. (2011). The toxic continuum from incivility to violence: What can HRD do? Advances in Developing Human Resources, 13, 3-9.

Goldberg, L. R. (1990). An alternative "description of personality": The Big-Five factor structure. Journal of Personality and Social Psychology, 59, 1216-1229.

Goldberg, L. R. (1992). The development of markers for the Big-Five factor structure. Psychological Assessment, 4, 26-42.

Griffiths, A. (1998). Work-related illness in Great Britain. Work and Stress, 12, 1-5.

Hayes, A. F. (2012). PROCESS: A versatile computational tool for observed variable mediation, moderation, and conditional process modeling [White paper]. Retrieved from http://www.afhayes.com/public/process2012.pdf 
Hodgson, J. T., Jones, J. R., Elliott, R. C., \& Osman, J. (1993). Self-reported work-related illness. Sudbury, Suffolk: HSE Books, (Research paper 33).

Karasek, R. (1979). Job demands, job decision latitude, and mental strain: Implications for job redesign. Administrative Science Quarterly, 24, 285-308.

Lazarus, R. \& Folkman, S. (1984). Stress, appraisal, and coping. New York: Springer Publishing.

Lim, S., Cortina, L. M., \& Magley, V. J. (2008). Personal and workgroup incivility: Impact on work and health outcomes. Journal of Applied Psychology, 93, 95-107.

McCrae, R. R, \& Costa, P. T. (1987). Validation of the five-factor model of personality across instruments and observers. Journal of Personality and Social Psychology, 52, 81-90.

Mark, G. M., \& Smith, A. P. (2008). Stress models: A review and suggested new direction. Vol. 3. EAOHP series. Edited by J. Houdmont S. Leka. Nottingham University Press. 111-144.

Ostry, A. S., Kelly, S., Demers, P. A., Mustard, C. M., \& Hertzman, C. (2003). A comparison between the effort-reward imbalance and demand control models. Biomedical Central Public Health, 3.

Pearson, C. M., Andersson, L. M., \& Wegner, J. W. (2001). When workers flout convention: A study of workplace incivility. Human Relations, 54, 1387-1419.

Porath, C., \& Pearson, C. (2013). The price of incivility. Harvard Business Review, 91, 115-121.

Probst, T. M. (2010). Multi-level models of stress and well-being. Stress and Health, 26, 95-97.

Reio, T. G., Jr. (2010). The threat of common method variance bias to theory building. Human Resource Development Review, 9, 405-411.

Reio, T. G., Jr. (2011). Supervisor and coworker incivility: Testing the work frustration-aggression model. Advances in Developing Human Resources, 13, 54-68.

Reio, T. G., Jr., \& Ghosh, R. (2009). Antecedents and outcomes of workplace incivility: Implications for human resource development research and practice. Human Resource Development Quarterly, 20, 237-264.

Reio, T. G., Jr., \& Sanders-Reio, J. (2011). Thinking about workplace engagement: Does supervisor and coworker incivility really matter? Advances in Developing Human Resources, 13, 462- 478.

Robinson, S. L., \& Bennett, R. J. (1995). A typology of deviant workplace behaviors: A multidimensional scaling study. Academy of Management Journal, 38, 555-572.

Roberts, S. J., Scherer, L. L., \& Bowyer, C. J. (2011). Job stress and incivility: What role does psychological capital play? Journal of Leadership and Organizational Studies, 18, 449-458.

Schabracq, M. A., \& Cooper, C. L. (2000). The changing nature of work and stress. Journal of Managerial Psychology, 15, 227-241.

Schilpzand, P., De Pater, I. E., \& Erez, A. (2016). Workplace incivility: A review of the literature and agenda for future research. Journal of Organizational Behavior, 37, S57-S88.

Selye, H. (1936). A syndrome produced by diverse noxious agents. Nature, 138, 32.

Spector, P. E. (1998). A control theory of the job stress process. In C.L. Cooper (Ed.) Theories of organizational stress. New York: Oxford Press.

Spector, P. E. (2002). Employee control and occupational stress. Current Directions in Psychological Science, 4, 133-136.

Spector, P. E., \& Jex, S. M. (1998). Development of four self-report measures of job stressors and strain: Interpersonal conflict at work scale, organizational constraint scale, quantitative workload inventory, and physical symptoms inventory. Journal of Occupational Health Psychology, 3, 356-367.

Strahan R., \& Gerbasi, K. C. (1972). Short homogeneous versions of the Marlowe-Crowne Social Desirability Scale. Journal of Clinical Psychology, 28, 191- 193.

Theorell, T., Emdad, R., Arnetz, B., \& Weingarten, A. M. (2001). Employee effects of an educational program for managers at an insurance company. Psychosomatic Medicine, 63, 724-733.

Topolewska, E., Skimina, E., Strus, W., Cieciuch, J., \& Rowinski, T. (2014). The short ipip-bfm-20 questionnaire for measuring the big five. Annals of Psychology, 17, 385-402.

Wang, J., \& Pattern, S. B. (2001). Perceived work stress and major depression in the Canadian employed population, 20-49 years old. Journal of Occupational Health Psychology, 6, 283-289. 